\title{
THE EFFECT OF AORTIC CONSTRICTION ON ALDOSTERONE SECRETION IN HYPOPHYSECTOMIZED DOGS *
}

\author{
By WILLIAM F. GANONG AND PATRICK J. MULROW
}

(From the Department of Physiology, University of California School of Medicine, San Francisco, Calif.; and the Medical Service, VA Hospital, West Haven, and Department of Medicine, Yale University School of Medicine, New Haven, Conn.)

(Submitted for publication December 29, 1961 ; accepted February 26, 1962)

Nephrectomy inhibits the increase in aldosterone secretion caused by hemorrhage in hypophysectomized dogs $(1,2)$. Kidney extracts, renin preparations, and synthetic angiotensin II increase aldosterone secretion in nephrectomized, hypophysectomized dogs (3-6). Since hemorrhage leads to increased renin secretion $(7,8)$, it seems probable that the increase in aldosterone secretion after hemorrhage in hypophysectomized dogs is mediated by the renin-angiotensin mechanism. If this hypothesis is true, other stimuli that have been used to increase renin secretion should cause a rise in aldosterone output. Constriction of the aorta above the origin of the renal arteries appears to be such a stimulus $(9,10)$. The present study demonstrates that constriction of the aorta above the renal arteries can stimulate aldosterone secretion.

\section{METHODS}

Six or more days after removal of the right adrenal, nine male mongrel dogs, weighing 9.6 to $16.9 \mathrm{~kg}$, were anesthetized with pentobarbital. In each dog the left adrenal vein was cannulated (11) and strips of umbilical tape were passed around the aorta above and below the origin of the renal arteries. The ends of each strip were passed through pieces of Lucite tubing to form a choker (Figure 1). The upper choker was below the left lumboadrenal artery. The right lumboadrenal artery, which arises from the aorta near the right renal artery, had been tied at the time of right adrenalectomy. The lumbar arteries leaving the aorta between the two chokers were ligated. A polyethylene cannula for monitoring aortic blood pressure was inserted into the aorta through one of the femoral arteries until its tip was just below the lower choker. Cannulae were also placed in one femoral vein and one carotid artery. The abdominal wound was sutured and the animal hypophysectomized via the transbuccal route. Starting 1.5 hours later, adrenal venous blood specimens were collected in heparinized centrifuge

* This work has been supported by Grants A-3818 and C-3998 from the U. S. Public Health Service and by a grant-in-aid from the Commonwealth Fund. tubes. Carotid and aortic blood pressure was monitored continuously, with Statham strain gauges and a Grass model 4 polygraph. After each sample of adrenal venous blood was collected, an equal volume (12 to $16 \mathrm{ml}$ ) of bank blood from nephrectomized, hypophysectomized donor animals was infused into the femoral vein. After two control adrenal venous blood samples at 20 -minute intervals, the choker below the renal arteries was tightened until the mean pressure in the aorta below it was reduced by approximately 50 per cent. Adrenal venous blood samples were collected 10 and 30 minutes after constriction, and the choker was then released. After another adrenal venous sample 20 minutes later, the upper choker was tightened until aortic pressure again fell approximately 50 per cent. Adrenal venous blood samples were obtained $10,30,60,90$, and 120 minutes after tightening the upper choker. With the aorta still constricted above the renal arteries, $100 \mathrm{mU}$ ( 2 dogs) or $1,000 \mathrm{mU}$ (4 dogs) of ACTH (Upjohn) was then injected and an adrenal venous blood sample collection started 4 minutes later.

Adrenal venous blood samples were centrifuged promptly and the frozen plasma was stored. Aldosterone and corticosterone were measured by the double isotope derivative technique (12); 17-hydroxycorticoids were determined by the Silber-Porter method (13). The output of

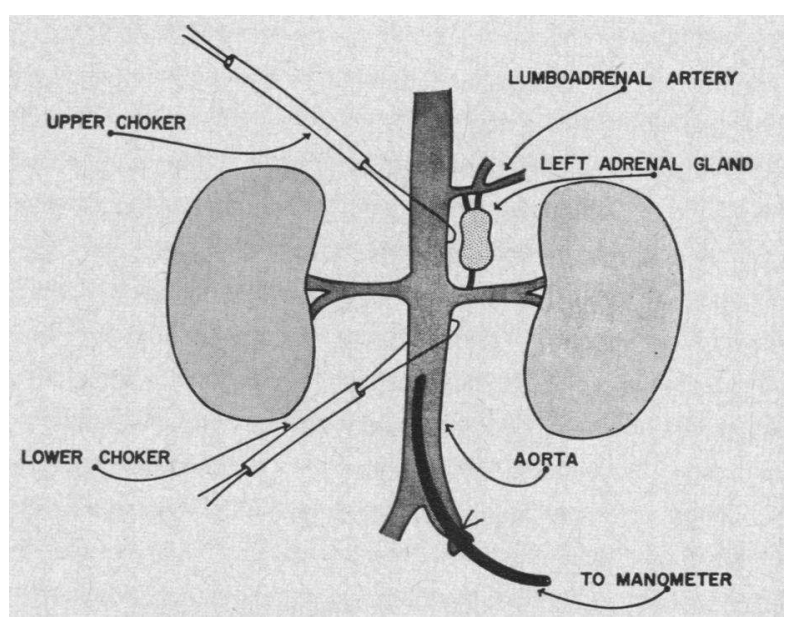

Fig. 1. ArRangement of ChOKers for PRODUCING INFRA- AND SUPRARENAL AORTIC CONSTRICTION IN HYPOPHYSECTOMIZED DOGS. Only arterial circulation is shown. 
WILLIAM F. GANONG AND PATRICK J. MULROW

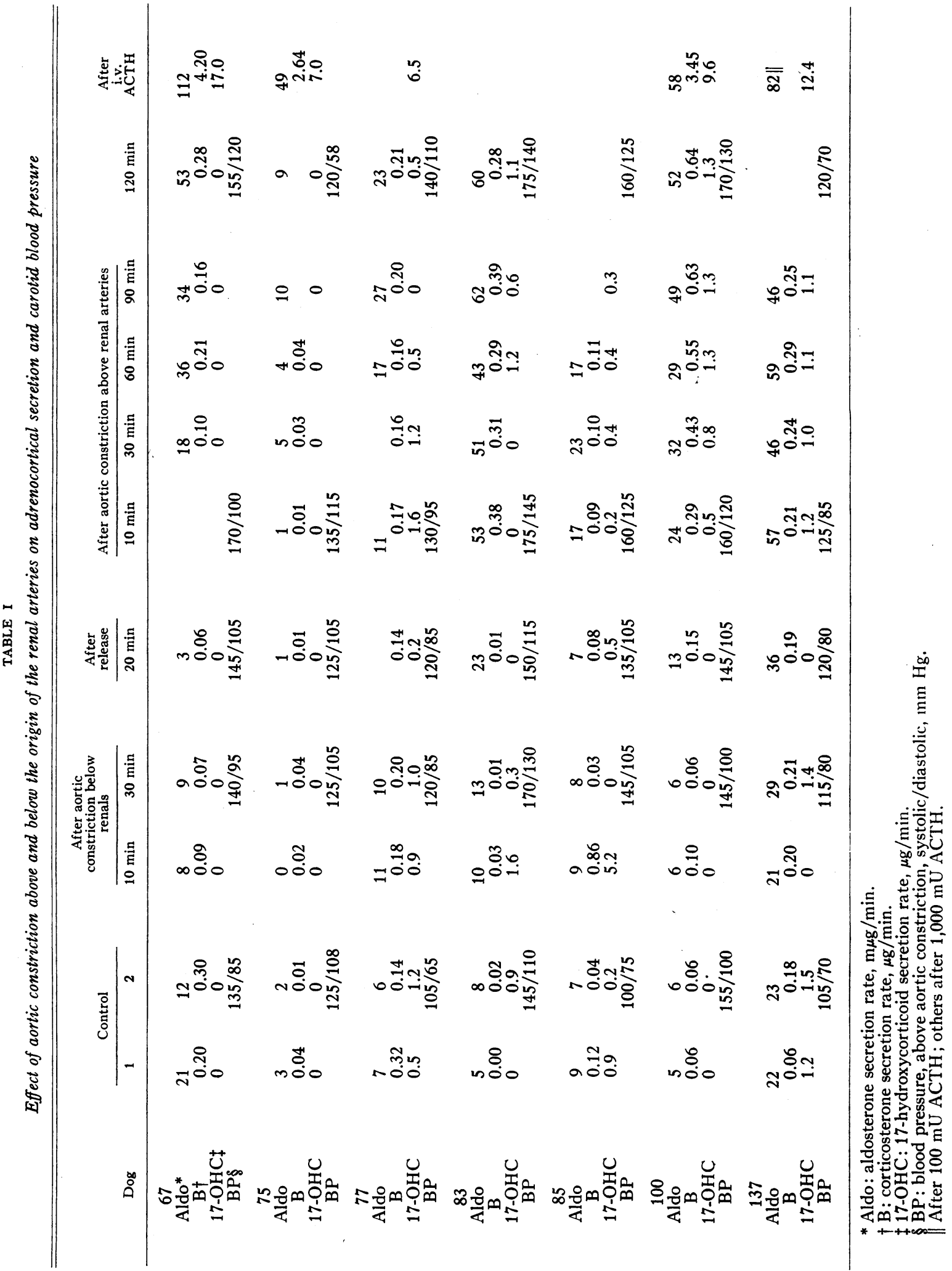


each of these hormones was calculated by multiplying its concentration in adrenal venous plasma by the adrenal venous plasma flow per minute. The position of the chokers was verified at autopsy, and the completeness of hypophysectomy was determined by gross examination of the sella turcica and hypothalamus.

In one dog the aorta and vena cava were tied immediately below the renal vessels and the dog hypophysectomized. Starting 1.5 hours later, two control adrenal venous blood samples were collected. The aorta was then constricted above the origin of the renal arteries and adrenal venous blood samples collected as described.

\section{RESULTS}

The aldosterone, corticosterone, and 17-hydroxycorticoid secretion values are shown in Table $I$, and summarized in Figure 2. Aldosterone secretion rose after constriction above the renal arteries in every dog, whereas constriction below the renal arteries produced no consistent change. The mean aldosterone secretion rate after constriction above the renal arteries is significantly greater than the mean secretion rates during the control period, or after constriction below the renal arteries, or after release $(p<0.01,0.001,0.01$, respectively, by the two-sided paired $t$ test). A slight rise in 17hydroxycorticoid secretion followed tightening of the upper choker in four dogs. Corticosterone secretion increased in four of the eight dogs in which it was measured, but the mean corticosterone secretion rate after constriction above the renal arteries was not significantly greater, by the two-sided paired $t$ test, than were the mean corticosterone secretion rates during the control period, or after constriction below the renal arteries, or after release. In $\operatorname{dog} 85$, both 17 -hydroxycorticoid and corticosterone secretion increased 10 minutes after constriction below the renal arteries, but no change in aldosterone secretion occurred. At all other times in this dog, and except after ACTH in the other dogs, 17-hydroxycorticoid and corticosterone secretion rates were within the range seen in hypophysectomized dogs. In three instances (dogs $83,100,137$ ), there was a moderate rise in aldosterone secretion after releasing the lower choker.

Adrenal venous blood flow was generally unaffected by tightening either choker. Corticosterone and aldosterone secretion, as well as 17-hydroxycorticoid secretion, increased significantly after intravenous administration of ACTH. Blood 


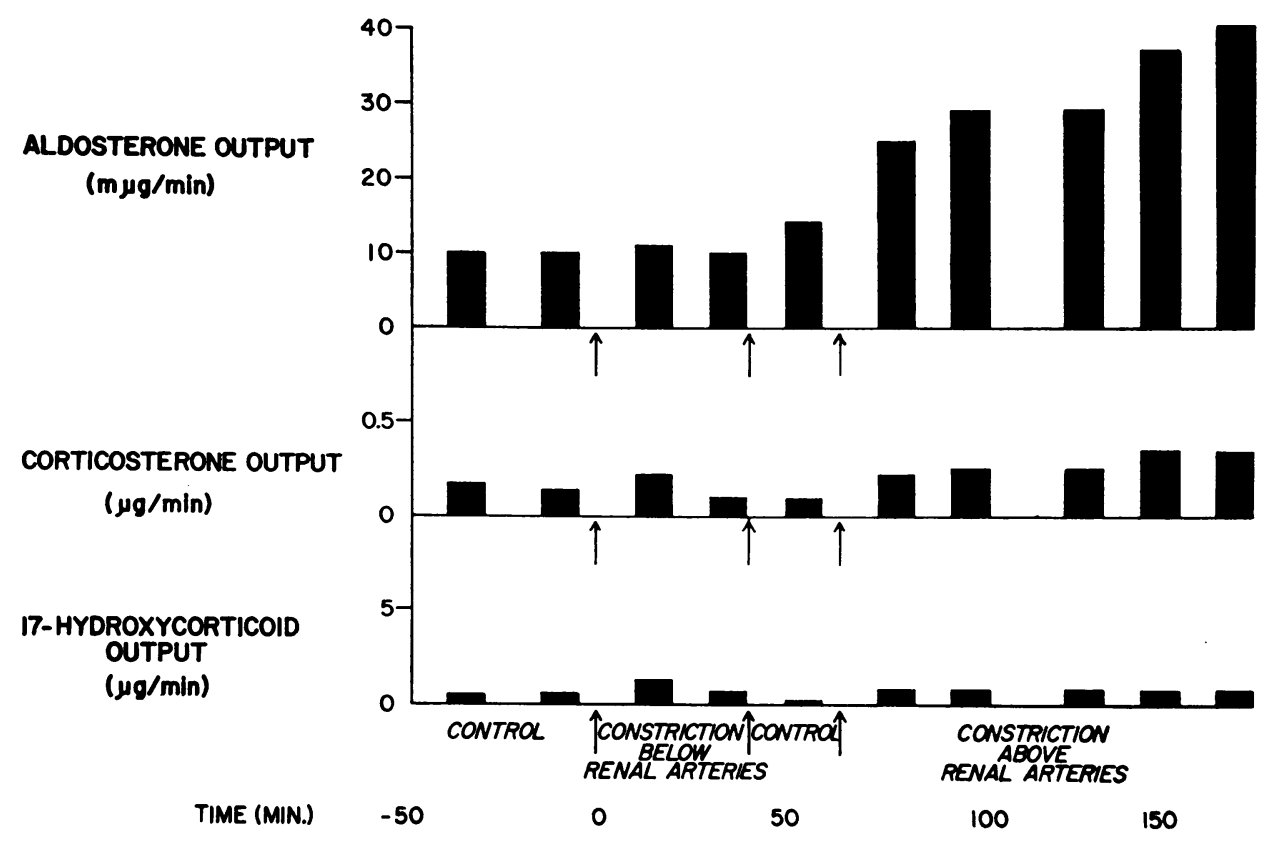

Fig. 2. Summary of EFFECt of aORTIC CONStriction above and below the origin of the RENAL ARTERIES ON ADRENOCORTICAL SECRETION. The first arrow marks the time at which the aorta was constricted below the renal arteries, the second the time at which this constriction was released, and the third the time at which the aorta was constricted above the renal arteries. Values are means of data in Table I.

pressure above the constriction was usually increased by aortic constriction below the renal arteries and remained slightly elevated even when the constriction was released. The rise in blood pressure after constriction of the aorta above the renal arteries was more rapid in onset and greater than that after constriction below the renal arteries. The elevated blood pressure was generally maintained until the end of the experiment.

Gross examination of the pituitary fossa revealed no pituitary remnants in any of the dogs. In dog 77 there were two left renal arteries, one of which was above the upper choker. However. the dog still showed a marked increase in aldosterone secretion after aortic constriction.

\section{DISCUSSION}

Constriction of the aorta above the renal arteries has been shown to increase renin release from the kidney (10). Injections of renin and angiotensin II have been shown to stimulate aldosterone secretion (3-6). The increase in aldosterone secretion produced by constriction of the aorta above the renal arteries is therefore probably mediated by the renin-angiotensin mechanism. It is unlikely that constriction of the aorta stimulated aldosterone secretion by altering adrenal hemodynamics. The site of constriction was below the left lumboadrenal artery, and constriction did not alter adrenal blood flow significantly. Moreover, hemorrhage usually decreases adrenal blood flow in nephrectomized, hypophysectomized dogs, but aldosterone secretion is not increased, and infusion of norepinephrine in doses that cause marked increases in systemic blood pressure have no effect on aldosterone secretion in the $\operatorname{dog}(4)$.

Carpenter, Davis and Ayers (5) did not find elevated aldosterone secretion rates 3 to 21 days after renal arterial constriction in the dog. unless "malignant hypertension" had developed. There is considerable evidence, however, that the increase in renin secretion after constriction of the renal blood supply is a transient phenomenon, and that renin secretion declines during prolonged periods of constriction, even though the blood pressure remains elevated (14-16). This may also explain why elevated aldosterone secretion is not seen in all patients with hypertension due to uni- 
lateral renal ischemia. Recently, Davis and his associates have stated in an abstract (17) that they also find a prompt rise in aldosterone secretion after aortic constriction above the renal arteries in hypophysectomized dogs.

The moderate rise in aldosterone secretion in three dogs after release of the aortic constriction below the renal arteries is unexplained. The effects of infrarenal aortic constriction on the kidney are a matter of controversy. Renal shut-down and azotemia are recognized complications of abdominal aortic aneurysmectomy (18). Powers, Boba and Stein (19) have reported decreased renal blood flow in dogs after infrarenal aortic occlusion, but others have failed to confirm this observation (17). Nanson and Noble (20) reported production of renal tubular necrosis following infrarenal aortic occlusion for 2 hours, and claimed that they could prevent this complication by infiltrating the renal pedicle with a local anesthetic. The latter finding suggests that the necrosis was secondary to changes in the renal arterial vessels. It is possible, therefore, that some renal ischemia occurred in our dogs during infrarenal aortic constriction, and that this was sufficient in three cases to lead to release of small amounts of renin. This may have contributed to the elevation in blood pressure after such constriction, although most of the increase was probably due to the increase in peripheral resistance produced by the constriction. However, in the one $d o g$ in which the aorta and vena cava were ligated below the kidneys 1 hour before the collection of the control adrenal venous samples, aldosterone secretion was not elevated. Constriction of the aorta above the renal arteries in this dog produced a marked rise in aldosterone secretion.

The rise in aldosterone secretion after aortic constriction in dog 77 indicates that such increases can occur when the arterial supply to part of the kidney is intact. This animal had two left renal arteries, and the upper choker was inadvertently placed below one of these vessels.

The location of the "volume receptor" which initiates the events leading to increased aldosterone secretion has been a subject of considerable debate. Gann, Mills and Bartter (21) suggested that it was at the junction of the thyroid and carotid arteries, and that decreased carotid pulse pressure was the hemodynamic parameter responsible for increased aldosterone secretion. Carotid pulse pressure in our experiments was unchanged or even increased, whereas a decrease in arterial mean and pulse pressure in the kidney was associated with increased aldosterone secretion. A change in either or both of these parameters is known to increase renin secretion (9).

It has been claimed that the renal nerves are not necessary for the increased release of renin that follows constriction of the renal artery. Tobian $(22,23)$ has suggested that the juxtaglomerular cells not only secrete renin, but function as "volume receptors." Our results are consistent with this hypothesis. It is possible, therefore, that changes in the renal arterial circulation lead directly to renin release and stimulation of aldosterone secretion, and that the nervous system is not part of this regulatory mechanism.

\section{SUMMARY}

The effect on adrenocortical secretion of constricting the aorta above and below the origin of the renal arteries has been investigated in hypophysectomized dogs. Constriction above the renal arteries caused an increase in aldosterone secretion in every case. Constriction below the renal arteries had no consistent effect.

\section{ACKNOWLEDGMENTS}

The authors wish to acknowledge the technical assistance of Mrs. Vessla Loken, Mrs. Lea Tripodi, Mr. Roy Shackleford, Mrs. Annette Low, Miss Angela Boryczka, Mr. Albert Kuljian, Mr. Walter Herniak and Miss Patricia Tomasi. The ACTH used in these experiments was kindly supplied by Dr. J. Stucki of the Upjohn Company, Kalamazoo, Mich.

\section{REFERENCES}

1. Ganong, W. F., and Mulrow, P. J. Evidence of secretion of an aldosterone-stimulating substance by the kidney. Nature (Lond.) 1961, 190, 1115.

2. Davis, J. O., Carpenter, C. C. J., Ayers, C. R., Holman, J. E., and Bahn, R. C. Evidence for secretion of an aldosterone-stimulating hormone by the kidney. J. clin. Invest. 1961, 40, 684.

3. Mulrow, P. J., and Ganong, W. F. Stimulation of aldosterone secretion by angiotensin II. A preliminary report. Yale J. Biol. Med. 1961, 33, 386.

4. Mulrow, P. J., and Ganong, W. F. The role of the kidney and the renin-angiotensin system in the response of aldosterone secretion to hemorrhage. Circulation 1961. In press. 
5. Carpenter, C. C. J., Davis, J. O., and Ayers, C. R. Relation of renin, angiotensin II and experimental renal hypertension to aldosterone secretion. J. clin. Invest. 1961, 40, 2026.

6. Bartter, F. C., Casper, A. G. T., Delea, C. S., and Slater, J. D. H. On the role of the kidney in control of adrenal steroid production. Metabolism 1961, 10, 1006.

7. Saperstein, L. A., Ogden, E., and Southard, F. D., Jr. Renin-like substance in blood after hemorrhage. Proc. Soc. exp. Biol. Med. (N.Y.) 1941, 48, 505.

8. Huidobro, F., and Braun-Menéndez, E. The secretion of renin by the intact kidney. Amer. J. Physiol. 1942, 137, 47.

9. Hawthorne, E. W., Perry, S. L. C., and Pogue, W. G. Development of experimental renal hypertension in the dog following reduction of renal artery pulse pressure without reducing mean pressure. Amer. J. Physiol. 1953, 174, 393.

10. Braun-Menéndez, E., Fasciolo, J. C., Leloir, L. F., Muñoz, J. M., and Taquini, A. C. Renal hypertension. L. Dexter, Trans. Springfield, Ill., Thomas, 1946.

11. Hume, D. M., and Nelson, D. H. Adrenal cortical function in surgical shock. Surg. Forum 1955, 5, 568.

12. Kliman, B., and Peterson, R. E. Double isotope derivative assay of aldosterone in biological extracts. J. biol. Chem. 1960, 235, 1639.

13. Silber, R. H., and Porter, C. C. The determination of 17, 21-dihydroxy-20-ketosteroids in urine and plasma. J. biol. Chem. 1954, 210, 923.

14. Floyer, M. A. The role of the kidney in the mechanism of experimental hypertension in Ciba Found.
Coll. on Hypertension, Humoral and Neurogenic Factors, G. E. W. Wolstenholme and M. P. Cameron, Eds. Boston, Little, Brown, 1954, p. 155.

15. Blaquier, P., Bohr, D. F., and Hoobler, S. W. Evidence against an increase in circulating pressor material in renal hypertensive rats. Amer. J. Physiol. 1960, 198, 1148.

16. Scornik, O. A., and Paladini, A. C. Angiotensin blood levels in dogs with experimental renal hypertension. Amer. J. Physiol. 1961, 201, 526.

17. Davis, J. O., Ayers, C. R., and Carpenter, C. C. J. The renin-angiotensin system in the control of aldosterone secretion. Physiologist 1961, 4, (Aug.) 27.

18. McGonigle, D. J., Seipel, R. S., and Wylie, E. J. Renal effects of temporary extensive infrarenal arterial occlusion: An experimental study. Surgery 1961, 49, 235.

19. Powers, S. F., Boba, A., and Stein, A. The mechanism and prevention of distal tubular necrosis following aneurysmectomy. Surgery 1957, 42, 156.

20. Nanson, E. M., and Noble, J. G. The effect on the kidneys of cross-clamping the abdominal aorta distal to the renal arteries. Surgery 1959, 46, 388.

21. Gann, D. S., Mills, I. H., and Bartter, F. C. On the hemodynamic parameter mediating increase in aldosterone secretion in the dog. Fed. Proc. 1960, 19, 605.

22. Tobian, L. Physiology of the juxtaglomerular cells. Ann. intern. Med. 1960, 52, 395.

23. Tobian, L. Interrelationship of electrolytes, juxtaglomerular cells and hypertension. Physiol. Rev. 1960, 40, 280. 